\title{
El activismo de la sociedad civil por la educación inclusiva en el campo judicial. Un estudio de caso*
}

\author{
Civil Society Activism for Inclusive Education in the Judicial Field. \\ A Case of Study \\ O ativismo da sociedade civil pela educação inclusiva no campo \\ judicial. Um estudo de caso
}

\author{
PILAR ARCIDIÁCONO* \\ LETICIA BARRERA ${ }^{* * *}$
}

FECHA DE RECEPCIÓN: 29 DE NOVIEMBRE DE 2017. FECHA DE APROBACIÓN: 10 DE ABRIL DE 2018

DOI: http://dx.doi.org/10.12804/revistas.urosario.edu.co/sociojuridicos/a.6303

Para citar este artículo: Arcidiácono, P. G Barrera, L. (2018). El activismo de la sociedad civil por la educación inclusiva en el campo judicial. Un estudio de caso. Estudios Socio-Jurídicos, 20(2), 51-76. doi: http://dx.doi.org/10.12804/revistas urosario.edu.co/sociojuridicos/a.6303

\section{RESUMEN}

Alan Rodríguez es un joven con síndrome de Down que, al finalizar la escuela secundaria en una escuela común de la Ciudad de Buenos Aires y tras haber aprobado todas las materias, no recibió su título secundario. En su reemplazo, obtuvo un certificado no oficial de graduado que no acredita la "terminalidad" de sus estudios. Esta situación motivó a que Alan y su familia promovieran una demanda judicial contra la escuela y contra el

* El artículo no ha sido presentado en algún congreso ni ha sido escrito para una ponencia. No hubo un financiamiento específico para este proyecto. Forma parte de las líneas de investigación de las autoras en el Sistema de Ciencia y Técnica de Argentina (CONICET). Las autoras agradecen a Dalile Antúnez, Celeste Fernández, Mariela Galeazzi, Adolfo Leguizamón y Gabriela Santuccione por compartir tan generosamente su tiempo y conocimiento acerca de los temas tratados en este artículo.

** Magíster en Políticas Sociales y doctora en Ciencias Sociales de la UBA. Investigadora adjunta de CONICET, investigadora permanente del Instituto de Investigaciones Jurídicas y Sociales Ambrosio L. Gioja (Facultad de Derecho-UBA), e investigadora del Grupo de Trabajo Interdisciplinario Derechos Sociales y Políticas Públicas. Profesora de Sociología Política de la carrera de Sociología de la UBA. Docente de posgrados relacionados con el campo de las políticas sociales (UBA-Universidad Nacional de La Plata). Correo electrónico: pilar.arcidiacono@gmail. com. ORCID://orcid.org/0000-0002-3847-9120

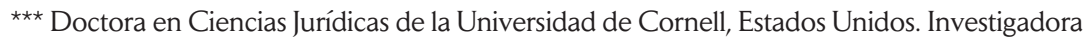
del CONICET con sede en el Instituto de Altos Estudios Sociales de la Universidad Nacional de San Martín, Argentina. Se especializa en el estudio del derecho y la práctica judicial desde una perspectiva sociocultural. Correo electrónico: leticiabarrera@yahoo.com. ORCID://orcid.org/00000002-7001-9378 
Gobierno de la Ciudad de Buenos Aires (GCBA) con el objeto de que se le hiciera entrega de su título oficial en igualdad de condiciones que a sus pares.

Desde el análisis de esta causa, en un contexto de activismo de la sociedad civil, el artículo aborda la educación inclusiva de las personas con discapacidad como un campo de tensiones y disputas entre diferentes actores sociales (sus prácticas, saberes, narrativas, y moralidades). Estos conflictos ponen en entredicho el enfoque social inclusivo de la discapacidad que articulan tratados, normas constitucionales y algunas leyes nacionales, dando curso a prácticas que desarrollan la inclusión educativa en un marco de incertidumbre y ambigüedad.

Palabras clave: activismo, inclusión educativa, discapacidad, judicialización.

\section{ABSTRACT}

Alan Rodriguez is a young man with Down syndrome who attended a private school in the mainstream school system in the City of Buenos Aires. However, after completing high school and despite having passed all subjects he did not receive his diploma. Instead, he got a nonofficial certificate that did no accredit "the completion" of his studies. Consequently, Alan and his family decided to file a law suit against the government of the City of Buenos Aires (GCBA) and the school demanding that they grant him the official certificate of graduation.

Drawing on the analysis of this judicial case, in a context of civil society's activism, this article approaches the subject of inclusive education of people with disabilities as a field of tensions and disputes that emerge among different social actors (and their practices, narratives, and moralities). These conflicts challenge the social approach to disability promoted by international treaties, constitutional norms and some national statutes. This, in turn, paves the way to practices that make inclusive education ambiguous and uncertain.

Keywords: activism, inclusive education, disability, judicialization.

\section{RESUMO}

Alan Rodríguez é um jovem com Síndrome de Down que ao finalizar a escola secundária em uma escola comum da cidade de Buenos Aires, e tendo aprovado todos os cursos, não recebeu seu título secundário. Em seu lugar, obteve um certificado não oficial de formado que não acredita a "terminalidade" de seus estudos. Esta situação motivou que Alan e a sua família promoveram uma demanda judicial contra a escola e o Governo da Cidade de Buenos Aires (GCBA) com o objetivo de que lhe fizera entrega de seu título oficial em igualdade de condições que seus pares.

Desde a análise desta causa em um contexto de ativismo da sociedade civil, o artigo aborda a educação inclusiva das pessoas com deficiência como um campo de tensões e disputas entre diferentes atores sociais (suas práticas, saberes, narrativas e moralidades). Estes conflitos põem em entredito o enfoque social inclusivo da deficiência que articulam tratados, normas constitucionais e algumas leis nacionais, dando curso a práticas que desenvolvem a inclusão educativa em um marco de incerteza e ambiguidade.

Palavras-chave: ativismo, educação inclusiva, judicialização, deficiência. 
“iAl fin una buenísima noticia. Era hora que se hagan valer los derechos del niño para 35 y no para uno solo!". "iiiQué bueno para los chicos!!! Que puedan trabajar y estar tranquilos".

\section{Introducción: la educación inclusiva como campo}

Los comentarios del epígrafe reproducen parte de una conversación en un grupo de WhatsApp entre madres de alumnos de una escuela privada en una localidad de la Provincia de Buenos Aires. En este intercambio, el grupo de madres celebraba que los directivos de la institución hubieran removido del curso de sus hijos a un alumno con síndrome de Asperger. Las capturas del chat se hicieron públicas a comienzos del mes de septiembre de 2017 y, rápidamente, se volvieron virales. Los medios de comunicación argentinos incluyeron en su agenda el tratamiento de este caso ${ }^{1}$ al incorporar, algunos, la información y opinión de especialistas que explicaban las características de este síndrome, sus matices en cuanto a causas y abordajes ${ }^{2}$ y las condiciones de vida de las personas con Asperger. Al mismo tiempo, el Instituto Nacional contra la Discriminación, Xenofobia y Racismo (INADI) intervino para asesorar a la familia del niño que había sido apartado y planificar, además, una visita a la escuela ${ }^{3}$.

La discriminación a personas con discapacidad, en diversos ámbitos, no resulta algo novedoso. Sin embargo, el caso mencionado, junto a otros que sucedieron en la Ciudad de Buenos Aires, en los últimos tiempos, dan cuenta de las dificultades que niños y jóvenes con discapacidad y sus familias enfrentan al transitar (o intentar hacerlo) su vida escolar en escuelas comunes. Estos casos, junto al que abordamos en este trabajo, no son hechos aislados. Trascienden la esfera de lo privado; captan la

Véase, por ejemplo: http://www.infobae.com/sociedad/2017/09/03/indignacion-enlas-redes-por-un-grupo-de-madres-festejo-la-desvinculacion-de-un-nene-con-asperger/

http://www.lanacion.com.ar/2059550-sindrome-asperger-nino-san-antonio-de-paduamadres-chat-whatsapp

https://www.clarin.com/sociedad/hablo-mama-chico-cambiaron-curso-tener-asperger-senti-verguenza-ajena_0_SJKEd7jF-.html

2 http://www.revistaanfibia.com/cronica/el-lenguaje-privado-del-autismo/

3 http://www.lanacion.com.ar/2059569-el-inadi-asesoro-a-la-familia-del-alumno-con-sindrome-de-asperger-y-fijo-una-visita-a-la-escuela 
atención de los medios de comunicación, de las organizaciones sociales, y logran, en algunas oportunidades - sobre todo al judicializarse- activar resortes estatales. Por otro lado, al poner de manifiesto los conflictos y las experiencias cotidianas de los actores, estos sucesos dan cuenta de las tensiones entre saberes, prácticas y narrativas que atraviesan la inclusión de las personas con discapacidad en las escuelas comunes, revelándola como un terreno de disputas.

Entendemos que el concepto de educación inclusiva es polisémico (Ainscow, Farrell \& Tweddle, 2000; Echeita, 2008). Parte de reconocer diversos grupos e individuos cuyo origen racial o étnico, clase social, género, o discapacidad operan como vectores de desigualdad que se reproducen en el sistema educativo y apela, como horizonte, a la necesidad de transformaciones que permitan el desarrollo de sus trayectorias educativas en igualdad de condiciones. En esta línea, UNESCO (2005) destaca que el término implica una reforma que acoge y apoya la diversidad entre todos los alumnos. Tres puntos sobre el abordaje de la educación inclusiva en este artículo.

Primero, nos concentraremos en una dimensión propia de la educación inclusiva. Se trata de su convergencia con el campo de la discapacidad, aspecto recogido por la normativa vigente, específicamente por el Artículo 24 de la Convención sobre los Derechos de las Personas con Discapacidad de la $\mathrm{ONU}^{4}$ (tratado que en Argentina cuenta con jerarquía constitucional): "Los Estados parte reconocen el derecho de las personas con discapacidad a la educación. Con miras a hacer efectivo este derecho sin discriminación y sobre la base de la igualdad de oportunidades, los Estados parte asegurarán un sistema de educación inclusivo a todos los niveles así como la enseñanza a lo largo de la vida".

Nos interesa esto en la medida en que, si bien el marco constitucional argentino favorece la inclusión educativa a partir de la ratificación de la Convención, el acceso y la continuidad de las personas con discapacidad en un sistema de educación común no resulta tarea sencilla. Barreras económicas, burocráticas, o de otra índole-como el desconocimiento o 
desinterés en contemplar situaciones que no se ajustan a los parámetros esperados por la escuela- se conjugan como obstáculos para la igualdad ${ }^{5}$.

Segundo, nuestro acceso a este amplio campo se dio por el análisis del caso de Alan Rodríguez, un joven con síndrome de Down que, al finalizar la escuela secundaria en una escuela privada común de la Ciudad Autónoma de Buenos Aires (CABA), y pese a haber aprobado todas las materias, no recibió su título secundario sino que en su reemplazo obtuvo un diploma no oficial de graduado; un certificado que no acredita la "terminalidad" de sus estudios. Como se explicará en detalle más adelante, Alan y su familia decidieron promover una demanda judicial contra el Gobierno de la Ciudad de Buenos Aires (GCBA) y la escuela con el objeto de que se le entregara dicho certificado oficial ${ }^{6}$. El trabajar con y desde esta causa hizo posible, no solamente un conocimiento de las relaciones, los conflictos, los acuerdos, los saberes y las prácticas que se activan en relación con la inclusión educativa de personas con discapacidad, sino también reflexionar acerca de cómo estos impactan recursivamente $^{7}$ en la discusión de la política pública (Arcidiácono $\mathcal{G}$ Barrera, (mimeo) 2017).

Buscamos aproximarnos al tema desde la descripción y el análisis de determinadas prácticas de los actores en el entramado de un caso judicial que puede considerarse como "punta de lanza", específicamente en

5 La Asociación por los Derechos Civiles (ADC) elaboró un Manual de Buenas Prácticas en materia de Educación Inclusiva. Recuperado de http://www.adc.org.ar/wp-content/ uploads/2015/05/Buenas-practicas-Educacion-Inclusiva-ADC-2015.pdf

Asimismo, en mayo de 2017, la Comisión para la Plena Participación e Inclusión de las Personas con Discapacidad (COPIDIS) y el Grupo Artículo 24 por la Educación Inclusiva publicaron Educación inclusiva y de calidad. Un derecho de todos. Recuperado de http://acij.org.ar/wp-content/ uploads/2017/08/manual_educacion_inclusiva.pdf

6 Rodríguez, César Alan c/GCBA y otros s/Amparo Expte A. 47249-2015/0. En este trabajo se hace uso del verdadero nombre de Alan Rodríguez. En primer lugar, porque se trata de un caso judicial que tomó estado público, en el que Alan se presenta en la causa en primera persona reclamando su derecho al título. En segundo lugar, porque Alan se convierte en un referente público y mediático junto con su familia, la organización que patrocina y el resto de la alianza que impulsa el caso como parte de la estrategia de incidencia. Como se verá en las siguientes páginas, Alan es protagonista de diversas campañas que permiten instalar la temática en la agenda pública, mediática y estatal.

7 La noción de "recursividad" planteada por Adelantado et al. (1998) se alimenta de la teoría de la estructuración de Giddens para plantear una interacción recurrente y de influencia recíproca entre la práctica asociada a la política social y la estructura social al identificar procesos y efectos de larga duración que se manifiestan de manera más episódica. 
el proceso de reforma de la política pública en materia de titulación de personas con discapacidad que estudian en establecimientos comunes ${ }^{8}$.

Tercero, en la praxis, la educación inclusiva emerge como un campo, si se entiende con la misma acepción de Bourdieu: una categoría analítica que contribuye a captar el sentido del juego social y a explicar y comprender determinadas prácticas de los agentes sociales (Bourdieu, 1994). Este campo, no obstante, se nos fue presentando como una red de relaciones más que como un espacio cerrado o semiautónomo. Desde esta perspectiva es posible ver las tensiones y conflictos que asoman en la interacción de diferentes prácticas, percepciones, representaciones y estrategias de los actores respecto a la inclusión de personas con discapacidad. Este juego, sostenemos, va moldeando la relación entre discapacidad e inclusión, dentro y fuera de la estructura estatal.

\section{Acerca de la estrategia teórico- metodológica}

Indagar sobre la relación entre discapacidad y educación, desde el estudio de un caso judicial, responde a una estrategia metodológica frecuente en la antropología jurídica. El análisis del conflicto, de las disputas -el trouble-case method que adquiere forma en The Cheyenne Way de Llewellyn y Adamson Hoebel (1941)-, permite entenderlas no como fenómenos aislados de lo social, sino como las consecuencias de relaciones culturalmente situadas (Nader, 1969). Trabajar con una causa judicial, sostiene Sarrabayrouse Oliveira (2011, p. 34) no implica realizar un análisis de doctrina jurídica y conceptos dogmáticos, sino reconstruir y dar cuenta de las prácticas, los procedimientos, las relaciones y las tramas que caracterizan y articulan el universo social que se estudia (en el caso de esta autora, el de la justicia criminal federal argentina). Asimismo, siguiendo a de Sousa Santos (1991), Sarrabayrouse señala que el "trabajo con una causa judicial también puede ser pensado como aquello que Boaventura de Sousa Santos (1991) ha definido como método del caso

8 Trabajos como los de Bariffi y Palacios (2012) y Palacios (2008) ofrecen una mirada normativa sobre educación inclusiva de personas con discapacidad en el caso argentino mientras que otros como Grimaldi et al. (2016) y Skilar (2005) pueden brindar una aproximación al tema desde una perspectiva pedagógica. 
ampliado" (Sarrabayrouse Oliveira, 2011, p. 34). Según de Sousa Santos, "este método opone a la generalización positivista por la cantidad y por la informalización de las observaciones, la generalización por la calidad y por la ejemplaridad. En vez de fijar la cantidad de casos (observaciones) adecuada, el método del caso ampliado escoge un caso o número limitado de casos en los que se condensan con particular incidencia los vectores más importantes de las economías interaccionales de los diferentes participantes en una práctica social dada" (de Sousa Santos, 1991, p. 11; citado en Sarrabayrouse Oliveira, 2013, p. 34).

Esta metodología se complementa con entrevistas semiestructuradas realizadas a diferentes activistas de la educación inclusiva en el marco de sus trabajos en organizaciones de la sociedad civil - sea que se trate de entidades dedicadas al patrocinio jurídico o a la promoción e implementación de políticas públicas-, y a agentes del poder judicial. Asimismo, se mantuvieron conversaciones con padres de niños con discapacidad que asisten a escuelas comunes y que promovieron exitosamente demandas judiciales en reclamo de prestaciones de apoyo a la integración escolar de sus hijos. El hecho de no dirigir este último tipo de encuentros, celebrados en diferentes situaciones sociales, contribuyó en nuestra investigación a "corregir la tendencia a la imposición del marco del investigador" (Guber, 2010, p. 74), lo que posibilitó la incorporación de temáticas e intereses del universo de los actores además de empezar a preguntar por ellas (Guber, 2010, p. 74). Desde este registro, rico en comentarios, anécdotas personales, historias de vida, trayectorias familiares y hasta profesionales, varios actores ocuparon en nuestro campo un lugar de "compañeros intelectuales en la pesquisa" (Marcus, 1998, p. 69), lejos del esquema tradicional de investigador e informante clave. Cabe destacar que la investigación que dio origen a este artículo reúne dos líneas de trabajo diferentes acerca de las burocracias y la política pública, desarrolladas previamente por cada una de sus autoras. Sin duda, esto impacta en el abordaje teórico metodológico de este caso.

Por un lado, se parte de un interés en los aspectos materiales de la producción del saber burocrático (registros, expedientes, documentos), para avanzar luego en la preocupación por los efectos de la práctica burocrática en la adjudicación (o denegación) de derechos sociales y en la dinámica de la política pública. De este modo, el interés en los aspectos 
materiales de las burocracias permite detenerse en dispositivos que son centrales en la construcción de la causa judicial, tales como las prácticas de doble registro, secreto y discrecionalidad del establecimiento educativo, y el certificado de finalización de estudios secundarios - cuyos significados material y simbólico se hacen presentes en el proceso judicial justamente a partir de su ausencia-. Sobre este eje se construye, en parte, el argumento central del trabajo: ante aquello que la burocracia deniega -el certificado- se emplaza un sujeto de derechos que reclama, exige, demanda, la eliminación de las barreras que obstaculizan su derecho a una educación en el nivel superior en igualdad de condiciones. De este modo, se rechaza la mirada paternalista y tutelar que Estado y escuela ejercen sobre las personas con discapacidad y desde la que se tiende a definir el marco de posibilidades de sus desarrollos educativo y profesional ${ }^{9}$.

Por otro lado, el foco en la política pública permite ver de qué manera el resultado de la causa impacta en la legislación y en la formulación de políticas sobre discapacidad. Esto implica ubicar el caso en un marco interpretativo más amplio, no como un fenómeno aislado, sino como parte de una discusión contemporánea sobre el alcance y limitaciones de la educación inclusiva (por caso, el Artículo 24 de la Convención sobre los Derechos de las Personas con Discapacidad ${ }^{10}$ ) y, en ese contexto, pensar el activismo de la sociedad civil ante el poder judicial como un repertorio de acciones y estrategias que buscan impulsar modificaciones de política pública que otros poderes deniegan u omiten hacer efectivas.

9 En su libro, María Pía Venturiello (2016) trabaja con testimonios de personas con discapacidad motriz y sus familiares, los intercambios materiales y simbólicos que se dan en el interior de los vínculos cotidianos y vitales de estas personas, especialmente las trayectorias en las instituciones de salud. Allí encuentra posibilidades disponibles de inserción social en un contexto profundamente excluyente que, sin embargo, presenta intersticios desde dónde trazar un camino alternativo y construir otro tipo de subjetividades y vínculos.

10 “3. Los Estados parte asegurarán que las personas con discapacidad tengan acceso gene ral a la educación superior, la formación profesional, la educación para adultos y el aprendizaje durante toda la vida sin discriminación y en igualdad de condiciones con las demás. A tal fin, los Estados parte asegurarán que se realicen ajustes razonables para las personas con discapacidad". 


\section{El caso Alan Rodríguez}

\section{El telón de fondo: activismo, judicialización y derechos de las personas con discapacidad}

A partir del comienzo de este siglo, en América Latina, se produjo un incremento de la judicialización de las demandas vinculadas con la satisfacción de derechos sociales. Surgieron sentencias judiciales relevantes fundamentadas en instrumentos internacionales de derechos humanos sobre el derecho a la educación, a la salud, a la vivienda y a la seguridad social por parte de tribunales argentinos, costarricenses, brasileños y colombianos, por nombrar algunos (Arcidiácono et al., 2010; Bercovich \& Maurino, 2013; Abramovich \& Pautassi, 2009). Este escenario hizo posible, a la vez, un aumento del activismo de organizaciones sociales y de actores de la defensa pública que brindaron patrocinio y asesoramiento legal para el reclamo y la defensa de los derechos sociales vulnerados. Asimismo, organismos de derechos humanos fueron incorporando en su agenda este repertorio de derechos, y otras organizaciones comenzaron a tener una propia de litigio de casos individuales o colectivos, muchos de estos con pretensión estratégica (Bergallo, 2006).

La judicialización de los derechos sociales abre la posibilidad de que un juez ordene una reparación, tal como ocurre con la violación de un derecho civil o político, o bien de reclamar el cumplimiento de las obligaciones que constituyen el objeto del derecho (Artigas, 2005). Distintos factores se combinan para explicar el incremento de los reclamos judiciales vinculados con la satisfacción de derechos sociales en la región en el nuevo siglo: el proceso de democratización y la consecuente restauración del Estado de derecho; el deterioro de las condiciones económicas y sociales como consecuencia del proceso denominado de "ajuste estructural", que el periodo de recuperación posterior no logró resolver; la existencia de bloqueos o "callejones sin salida" en los canales tradicionales de la democracia representativa; la ausencia de respuestas adecuadas de los poderes ejecutivo y legislativo; reformas constitucionales que ampliaron el catálogo de derechos de ciudadanía garantizados por el Estado e incluyeron nuevas herramientas para su protección. Dicha formalización constitucional y legal abrió el camino de disputas y conflictos 
en el terreno judicial al incorporar, en un escenario corriente, la participación de los tribunales en diversas cuestiones políticas.

Esto transcurre en paralelo con una nueva ola de juridificación de cuestiones, que se encontraban reguladas de manera autónoma o informal (O’Donnell, 2008), con la consecuente penetración del campo jurídico (Bourdieu, 2000) en ámbitos sociales diversos, "publificando" asuntos privados, y redefiniendo e invadiendo relaciones domésticas e íntimas. El universo de la discapacidad no escapa a estas tendencias ${ }^{11}$.

Como ya se mencionó, Argentina adoptó la Convención de los Derechos de las Personas con Discapacidad mediante la aprobación de la Ley 26.378, el 21 de mayo de 2008 que, como tratado internacional, asume jerarquía superior a las leyes, de acuerdo con el Artículo 75, inciso 22, de la Constitución Nacional. Asimismo, en los últimos años, diversos documentos del sistema internacional fueron dando forma al nuevo corpus normativo que hace a la educación inclusiva de las personas con discapacidad $^{12}$, incluida la reciente Observación General Número 4 sobre el derecho a la educación inclusiva $(2016)^{13}$. Es necesario destacar que

11 A modo de ejemplo, para dar cuenta del nivel de judicialización, organizaciones de la sociedad civil que agrupan familiares de personas con discapacidad, junto con asociaciones profesionales del campo jurídico, organizan en la Ciudad de Buenos Aires sistemáticamente eventos sobre este tipo de problemáticas y abordajes. Para mayor información, cfr: http://apadea.org.ar/ eventos/vi-jornada-sobre-judicializacion-de-la-discapacidad/

12 Para mayor información, cfr. Oficina del Alto Comisionado de Naciones Unidas, Convención sobre los Derechos de las Personas con Discapacidad (2006); Oficina del Alto Comisionado de Naciones Unidas, Observaciones finales para Argentina del Comité sobre los Derechos de las Personas con Discapacidad (2012); Oficina del Alto Comisionado de Naciones Unidas para los Derechos Humanos, Estudio temático sobre el derecho de las personas con discapacidad a la educación (2013); Oficina del Alto Comisionado de Naciones Unidas, Comité sobre los Derechos de las personas con Discapacidad, Observación General Número 4 sobre el derecho a la educación inclusiva (2016).

13 En la Observación Número 4 del Comité sobre los Derechos de las Personas con Discapacidad, en las Observaciones finales se destaca "la importancia de reconocer las diferencias entre exclusión, segregación, integración e inclusión (...). La integración es un proceso consistente en ubicar a personas con discapacidad en instituciones educativas convencionales existentes, siempre que las primeras se puedan adaptar a los requerimientos estandarizados de tales instituciones. La inclusión implica un proceso de reforma sistémica que involucra cambios y modificaciones en el contenido, los métodos de enseñanza, enfoques, estructuras y estrategias en la educación para superar obstáculos con miras al objetivo de proveer a todos los estudiantes de la correspondiente franja etaria una experiencia de aprendizaje participativa y equitativa y el ambiente que mejor se corresponda con sus necesidades y preferencias. Colocar estudiantes con discapacidad en clases comunes sin que ello sea acompañado de cambios estructurales, por ejemplo, en la organización, currícula y en las estrategias de enseñanza y aprendizaje, no constituye inclusión. Por lo tanto, la integración no garantiza automáticamente la transición de segregación a inclusión". 
estos instrumentos jurídicos, como también la Ley Nacional 26.529 de Salud Mental, consagran un enfoque social de la discapacidad según el cual las causas de la desigualdad se sitúan en la sociedad y en la cultura de la normalidad y no en la persona con discapacidad. En consecuencia, de acuerdo con este paradigma/enfoque social, resulta necesario remover las barreras sociales que dificultan la inclusión de la personas con discapacidad para avanzar en el derecho a la igualdad y no discriminación (Monopoli \& Arriagada 2013, pp. 127-8). Esta mirada, que se opone abiertamente al modelo médico/rehabilitador, o clínico, que alcanzó su hegemonía durante el siglo $\mathrm{XX}^{14}$, implica un abordaje de la discapacidad que se refleja no solo en el trato social que se les ofrece a las personas, sino también en la fundamentación de las políticas públicas (Arcidiácono E Barrera, (mimeo) 2017). Según datos censales del año 2010, un 12,9\% de la población argentina tiene una discapacidad, lo que equivale a más de una de cada diez personas (Instituto Nacional de Estadística y Censo, INDEC, 2010).

El nuevo enfoque sobre la discapacidad resulta central para comprender lo que puede apreciarse como una mayor presencia de temas relacionados con esta en la agenda pública respecto a la vulneración de otros derechos. La discapacidad sale entonces de los intramuros del mundo familiar para hacerse pública (Ota de Leonardis, 1996). En muchos casos, "viejos problemas" comenzaron a presentarse en "clave de derechos" (Smulovitz, 2008), pero también aparecieron otras situaciones novedosas que encontraron un entorno habilitante. Así, fueron surgiendo numerosos litigios centrados sobre todo en las barreras para acceder a prestaciones no estrictamente médicas a las que están obligados los prestadores de salud (Abramovich \& Pautassi, 2008), además de una cantidad de casos vinculados con temáticas de seguridad social, por ejemplo el campo de las pensiones no contributivas por invalidez ${ }^{15}$ (Acuña \& Bulit Goñi, 2010). Sumado a esos tipos de causas, comenzaron a presentarse

14 Siguiendo a Diniz, Barboza y Dos Santos (2009), Monopoli y Arriagada describen al modelo clínico como un modo de comprender e interpretar la discapacidad a partir de una desventaja natural en el individuo. Ello implica que los esfuerzos deben concentrarse en reparar esas deficiencias, rehabilitando (desde lo psíquico, físico, o sensorial) para garantizar que todas las personas tengan un estándar de funcionamiento típico de la especie (Monopoli \& Arriagada 2013, p. 127).

15 Para consulta sobre casos que llegaron a la Corte Suprema de Justicia vinculados con 
algunas demandas (como la que aquí analizamos) de personas con discapacidad que antes no accedían a los espacios de educación común y, menos aún, al nivel secundario o universitario/terciario. Esto último se verifica también en un marco normativo que desde 2006 establece la obligatoriedad de la escuela secundaria en Argentina y coloca en cabeza del Estado el deber de asegurar el cumplimiento de dicha obligación (artículos 16 y 29 de la Ley de Educación Nacional 26.206).

En este contexto, el tema de la discapacidad y de la educación inclusiva atraviesa la agenda del litigio en derechos sociales. Los cambios normativos, las prácticas de familias y los propios procesos de inclusión educativa, iniciados por muchas escuelas, dieron origen, poco a poco, a numerosos litigios, muchos de los cuales tienen el fin de lograr la vacante de sus hijos/as en escuelas comunes, asegurar condiciones reales de inclusión, evitar la expulsión o, como en el caso que aquí analizamos, obtener la titulación después de haber cursado los años de escolaridad obligatoria. Es que, a pesar de que la integración es obligatoria para las escuelas, en la práctica muchos establecimientos educativos despliegan diversos repertorios - más o menos explícitos- que terminan expulsando a las personas con discapacidad ${ }^{16} \mathrm{u}$ obstaculizan su acceso a la educación superior ${ }^{17}$.

Las transformaciones a nivel de producción de derecho son impulsadas, reapropiadas y traducidas como demandas locales por el activismo de organizaciones de diverso tipo, muchas de las cuales participan en las mencionadas causas judiciales (como patrocinadores o como amicus curiae). La movilización legal de casos colectivos e individuales, patrocinados por organizaciones sociales (y también defensorías oficiales), fue ganando espacio como estrategia de acción política "por otros medios" y

discapacidad y la vulneración de diferentes derechos (educación, salud, seguridad social), cfr. Ministerio Público Fiscal (2017).

16 "L., M.B. c/ I.A.A.I. s/Amparo" y "Defensoría de Menores e Incapaces no. 6 c/ Colegio Mallinckrodt Hermanas de la Caridad s/ Amparo", ambos de 2017.

17 “Naranjo, Emiliano c/ Universidad de La Matanzal" (CSJ, 94, 2014, el 01/06/2015). En este caso, el máximo tribunal argentino, la Corte Suprema de Justicia de la Nación, rechazó el recurso de queja presentado por la Universidad Nacional de La Matanza (UNLaM) ya que Emiliano, graduado como licenciado en Educación Física en dicha institución, no podía acceder al profesorado universitario en razón de su discapacidad. Este caso es patrocinado por la Asociación por los Derechos Civiles (ADC), organización que actuó como amicus curiae en el caso de Alan. 
como espacio de canalización de demandas frente al Estado. En el campo de la discapacidad, como en el resto, los procesos de judicialización tienen efectos simbólicos (Mc Cann, 1991; Galanter, 1983): redefinen los temas de la agenda pública, estatal y mediática, las discusiones sobre aquello qué es legítimamente reivindicable, las prácticas e intervenciones que se habilitan, los problemas y los sujetos que pueden presentarse con el "permiso" (Heller, 1996) para reclamar.

\section{La construcción de la causa y del sujeto}

La situación escolar de Alan Rodríguez representa el universo de muchos niños, niñas y adolescentes con discapacidad que llevan adelante su escolarización en un establecimiento educativo común ${ }^{18}$. En la Ciudad de Buenos Aires, la integración escolar en escuelas comunes se realizaba, hasta el año 2016, conforme a lo establecido en la Disposición 25/ DGEGP/2011 (Dirección General de Educación de Gestión Privada de la Ciudad Autónoma de Buenos Aires). Según esta normativa, cuestionada por Alan y su familia en la demanda judicial, la modalidad de integración escolar debe llevarse a cabo siguiendo un proyecto pedagógico individual (PPI) que se diseña teniendo en cuenta metas personalizadas y una propuesta pedagógica-didáctica que atiende a las necesidades, los intereses y el desarrollo del máximo potencial de cada alumno/a ${ }^{19}$.

18 Resultaría arbitrario enumerar aquí las diversas condiciones que abren el camino a un proceso de integración escolar en escuelas comunes. Más allá de la obligación legal, depende, por un lado, de políticas y prácticas de las escuelas dispuestas en mayor o menor medida a incluir a personas con necesidades especiales y, por el otro, de distintos saberes expertos. En el campo de la salud mental, por ejemplo, neurólogos, psiquiatras, psicólogos, psicopedagogos, terapistas ocupacionales, fonoaudiólogos, emiten informes que se integran en la construcción de un diagnostico que, en la mayoría de los casos, se reproduce luego en un certificado oficial que acredita la condición de discapacidad de una persona. El certificado único de discapacidad (CUD) es expedido por el Ministerio de Salud de la Nación, tiene validez en todo el territorio nacional (Ley 22431, Artículo 3), y constituye condición sine qua non para la cobertura de las prestaciones debidas por parte de las obras sociales y del Estado, en forma subsidiaria. Es tal la entidad otorgada a este documento en el mundo de la discapacidad, que más que resultar declarativo, se ha convertido en un instrumento constitutivo de esta. Véase, por ejemplo, CSJN, "A., M. G. c/ Obra Social del Poder Judicial de la Nación s/ cobro de pesos/sumas de dinero", 05/09/12. Esta mirada formalista acerca del acceso a los derechos para las personas con discapacidad cuestiona, en los hechos, el enfoque inclusivo de la Convención Internacional por los Derechos de las Personas con Discapacidad, estableciendo mayores barreras burocráticas.

19 Esta modalidad se diferencia de la educación "especial". Está establecida en la Ley de Educación Nacional (Ley 26.206), destinada a "asegurar el derecho a la educación de las personas 
En caso de ser necesario, se realizan ajustes razonables en cuanto al contenido y a la metodología de aprendizaje. Los y las alumnas que cursan con integración escolar cuentan con la asistencia de una maestra integradora u otro personal acorde con las necesidades del caso (por ejemplo, un acompañante terapéutico). Esta norma también establecía que debía dejarse asentado en el boletín de calificaciones de cada estudiante que este o esta cursaba bajo la modalidad de integración escolar.

El estudio de este caso remite a un entramado burocrático que sitúa a la educación inclusiva en un territorio incierto y ambiguo, en el que se verifican prácticas de doble registro, discrecionalidad en la entrega de la certificación de estudios y, de secreto, al omitir el registro del curso bajo un PPI. Un caso previo al de Alan Rodríguez, que también planteó problemas para acceder al título secundario, fue el de Melina Quereilhac $^{20}$. Sin embargo, a diferencia del caso Rodríguez, en Quereilhac el establecimiento educativo involucrado no había dejado constancia en los documentos oficiales de la condición de discapacidad de su alumna. Esta modalidad de acción resulta una práctica bastante frecuente en la gestión de la educación de las personas con discapacidad en establecimientos escolares comunes. En conversaciones con nuestros interlocutores durante el trabajo de campo, varios coincidieron en señalar como cuestiones centrales aquellas vinculadas con la falta de registro y con el secreto lo que, en los hechos, se traduce en una invisibilización de la discapacidad. En otras palabras, los agentes escolares no registran los PPI de manera que, en el supuesto de que el alumno/a finalice sus estudios, se le otorga un título ordinario, es decir, "sin leyenda", no se deja constancia alguna de que estudió bajo la modalidad de integración. En otros casos, cuando sí se registraba el PPI, el texto de la mencionada Disposición 25/2011 dejaba un "vacío" que daba lugar a la expedición de un diploma

con discapacidades, temporales o permanentes, en todos los niveles y modalidades" (Artículo 42). A partir de los cambios normativos internacionales en materia de discapacidad, y específicamente en educación inclusiva, se aspira a la ampliación de la educación común como espacios para la formación y la socialización.

20 "Quereilhac, Melina c/GCBA s/Amparo", de Sala II CAyT in re EXP 31324, del 17/06/2014. La joven con síndrome de Down reclamaba su título al finalizar la escuela secundaria en el Instituto Modelo de Enseñanza Privada; demoró nueve años en conseguirlo. Tuvo un fallo a su favor del titular del Juzgado en lo Contencioso Administrativo porteño No. 2, Roberto Gallardo. Sin embargo, los propios protagonistas destacan que la mayor incidencia estuvo vinculada a la presencia del caso en el programa "Caiga quien Caiga"; 48 horas después obtuvo su título. 
"no oficial" de graduado, que no guardaba equivalencia con, ni tenía la misma validez que aquel otorgado a alumnos y alumnas que cursan sin integración escolar. Esta última práctica es la que viene a transparentar e impugnar el reclamo de Alan Rodríguez y su familia.

Asimismo, el análisis de este caso trae a luz una cuestión fundamental que no se aborda explícitamente en la causa judicial pero, a nuestro entender, atraviesa el campo de la educación inclusiva. Y es que, sin perjuicio de la vigencia de un enfoque social sobre la discapacidad -como se señaló antes, plasmado normativamente en un marco constitucional inclusivo-, los mecanismos concretos de inclusión de las personas con discapacidad, por caso, en el campo de la educación, están atravesados por un modo de interpretarla desde un enfoque medico/rehabilitador. Este último abordaje se cristaliza no solo en prácticas discriminatorias como las que dieron origen al amparo judicial interpuesto por Alan Rodríguez. También está presente en la institucionalidad de la política pública sobre discapacidad en Argentina, en tanto el conjunto de prestaciones básicas, las educativas entre ellas, se gestiona desde el sistema de salud $^{21}$. Entonces, aun cuando la causa no abre una discusión acerca de la vigencia del modelo médico, la sentencia judicial de primera instancia que hace lugar al reclamo, como se explicará más adelante, revela su pregnancia en las normas en materia de titulación a nivel federal y en las reacciones de las autoridades del GCBA que procuran "normalizar" al Otro, asimilarlo al resto para obtener sus mismos derechos. El problema, desde esta perspectiva, se encuentra en el niño o la niña, o adolescente con discapacidad que asiste a la escuela común y no logra, a los ojos de los agentes (escolares, estatales), satisfacer las condiciones generales que rigen la situación del resto de sus compañeros.

21 La Ley 24.901 establece el sistema de prestaciones básicas en habilitación y rehabilitación integral a favor de las personas con discapacidad. Concretamente, a través de las obras sociales a las que la ley obliga a brindar la totalidad de las prestaciones básicas que sus afiliados necesiten (esta obligación se extiende a los prestadores de medicina prepaga por los Artículos 1 y 7 de la Ley 26.682). En los casos en los que las personas con discapacidad o aquellos de quienes dependen no tengan obra social, el Estado, a través de sus organismos, se hace cargo de proveer las prestaciones básicas requeridas. En este marco, la educación de las personas con discapacidad no se plasma como un derecho, sino como una prestación que las obras sociales están obligadas a brindar a sus afiliados, y que el Estado asume subsidiariamente frente al sujeto que carece de cobertura médica. 
Por otra parte, a nivel de política pública, la causa vino a poner de manifiesto una falta de armonización entre los compromisos internacionales asumidos por Argentina en materia de derechos humanos de las personas con discapacidad y el sistema educativo. En particular, viejos esquemas de cursos y de titulación en la CABA que no se adecúan a los parámetros sostenidos por la convención en materia de educación inclusiva. En este desacople se transita y se despliegan diferentes dinámicas de las burocracias y de la política pública en las diferentes jurisdicciones.

La acción judicial fue patrocinada por la Asociación Civil por la Igualdad y la Justicia (ACIJ)22, institución que cuenta con más de quince años de trayectoria en el patrocinio jurídico de causas individuales y colectivas, además de resultar un actor clave en materia de litigio estratégico en la CABA. Esta organización incorporó en su propia agenda la temática de la educación inclusiva como un eje de trabajo sostenido. En el caso se presentaron amicus curiae de diferentes actores de peso en la materia ${ }^{23}$ que, con diversos argumentos, se manifestaron a favor de lo solicitado por Alan. Entre ellos se destaca el Grupo Artículo 24, coalición de más de 150 organizaciones en todo el país surgida en diciembre $2012^{24}$ y que tiene como eje de trabajo la garantía del derecho a la educación para todas las personas, con énfasis central en las personas con discapacidad.

En el texto de la demanda judicial, César Alan Rodríguez, en primera persona, expresa que tiene síndrome de Down y que transitó toda su escolaridad básica en la escuela común Jesús María de San Vicente de Paul, de la CABA. Pese a haber aprobado todas las materias, Alan no recibió su título secundario sino que obtuvo un diploma no oficial de graduado, de modo que no cuenta con un certificado que acredite con validez que finalizó el colegio secundario. A partir de esta situación, Alan y su familia promueven una acción de amparo contra el GCBA y contra la escuela con el objeto de que se le "entregue el certificado oficial de finalización de estudios secundarios y la demás documentación oficial

22 http://acij.org.ar/

23 Se presentaron el Instituto Nacional contra la Discriminación, Xenofobia y Racismo (INAD), el Dr. Carlos Skliar (investigador en el área de educación del CONICET, FLACSO), la Asociación por los Derechos Civiles (ADC).

24 Declaración de Principios del Grupo Artículo 24: http://www.grupoart24.org/documentos/declaracion-de-principios.pdf 
escolar que corresponda, en igualdad de condiciones que a [sus] demás compañeros" 25 .

La demanda señala, también, diversos derechos que se vulneran por no poder acceder a su título (como el derecho a trabajar y a estudiar) y hace hincapié en la situación de desigualdad, subordinación y segregación a la que es sometido. Esta decisión institucional es descrita como una barrera para su "proyecto de vida" con consecuencias morales y de salud que no solo son manifestación de la negativa a entregarle el título sino que se ven retroalimentadas a lo largo del proceso judicial (angustia, ansiedad, incomprensión).

La respuesta del GCBA (Ministerio de Educación) frente al reclamo judicial de Alan alega la existencia de un "vacío normativo". Es imposible, argumenta el gobierno -y también la escuela - otorgarle a Alan "la titulación pretendida por no haber alcanzado los contenidos mínimos que le permitieran la aprobación de la totalidad de las materias establecidas en el plan de Estudios de Bachiller (...). El haber cursado y aprobado sus estudios secundarios con contenidos curriculares adaptados, conforme lo exige la normativa de la CABA, no autoriza a la emisión de un título secundario, pero sí a la emisión de un certificado de asignaturas aprobadas" 26 .

Por el contrario, en paralelo al llamado "vacío normativo" que el gobierno y la escuela esgrimen como argumento jurídico para justificar su conducta, es posible entrever en estos actores un punto de vista moral acerca de la inclusión educativa de las personas con discapacidad. Como ya lo anticipáramos, de modo contrario a los lineamientos de un enfoque social de discapacidad que sostiene la necesidad de establecer trayectos escolares personales que posibiliten la inclusión educativa, la posición gubernamental hace hincapié en el requisito de que todos los alumnos aprueben en "iguales condiciones", lo que en otras palabras implica que los alumnos con discapacidad cumplan los contenidos mínimos educativos exigidos al resto de sus compañeros. Esta clave interpretativa se refleja, por ejemplo, en las palabras de la ministra de Educación de la CABA en el marco del expediente judicial: "no puede pretenderse que a la situación de Alan (...) se le dé el mismo tratamiento que a aquellos

\footnotetext{
25 "Rodríguez, César Alan c/GCBA y otros s/Amparo Expte A. 47249-2015/0".

26 "Rodríguez, César Alan c/GCBA y otros s/Amparo Expte A. 47249-2015/0".
} 
que sí aprobaron"27. Estos dichos van en sintonía con polémicas y repudiadas declaraciones públicas de esta misma funcionaria cuando afirmó ante la prensa "Nosotros [el gobierno] no sorteamos títulos, porque esto no es una rifa" 28 .

Por su parte, la sentencia de primera instancia -que quedó firme al rechazar la Cámara de Apelaciones los términos del recurso presentado en su contra por el GCBA- declaró para el caso de Alan la inconstitucionalidad de la normativa local, es decir la cuestionada Disposición 25/DGEGP/2011. De acuerdo al fallo, el texto legal en el que el GCBA y la escuela amparan su denegatoria resulta violatorio del principio de igualdad, discriminatorio y contrario a las disposiciones constitucionales locales, nacionales y convencionales en tanto no impone para todos los alumnos iguales condiciones para la certificación de los estudios secundarios y consecuente emisión del título.

En su análisis y decisión del caso, la magistrada de primera instancia elabora una línea argumental basada en la distinción que hace Ronald Dworkin (1988, p. 332) entre el derecho a igual tratamiento y el derecho a ser tratado como igual. En este sentido, la sentencia dispone que, "Adoptar el criterio de identidad de condiciones resultaría contrario a toda la implementación, diseño, finalidad y razón de ser de la educación inclusiva en tanto resultan inherentes a ella las nociones de ajustes razonables y enfoque individualizado, de modo tal que el exigir los conocimientos de la currícula general - no ajustada a la discapacidad que tiene el alumnono sería consecuente con sus rasgos característicos y definitorios" 29 . Más aun, en un giro que resulta novedoso en la jurisprudencia de los tribunales argentinos, interpreta la discapacidad como "categoría sospechosa", lo que implica que cualquier distinción o diferenciación que la norma efectúe en torno a esta condición de las personas exige el más estricto escrutinio o control de constitucionalidad por parte de los tribunales.

27 "Rodríguez, César Alan c/GCBA y otros s/Amparo Expte A. 47249-2015/0".

28 Comunicado oficial: http://www.telam.com.ar/notas/201603/141579-acuna-educacion-manipulacion-politica-joven-sindrome-down.html. Reacciones ante el comunicado: https://www.facebook.com/art24porlaEducacionInclusiva/photos /a.293167077490166.1073741839.278153975658143/648302788643258/?type=3Etheater

29 "Rodríguez, César Alan c/GCBA y otros s/Amparo Expte A. 47249-2015/0". 


\section{El caso de Alan Rodríguez como "punta de lanza"}

El Ministerio de Educación del GCBA reconoció en el expediente que, mientras tramitaba el caso de Alan, se realizaba un proceso de adecuación normativa a nivel del Consejo Federal de Educación, CFE (instancia de coordinación de la política educativa en el marco de la organización federal del Estado), para otorgar título oficial de nivel primario y secundario a los alumnos con discapacidad que estudien en escuela común, aun cuando lo hayan hecho con $\mathrm{PPI}^{30}$. Hasta aquí, estos argumentos recurrentes en el expediente judicial pueden ser interpretados en clave de "velo" (Auyero, 2013), es decir, se trata de una dinámica de las burocracias para enmascarar, detrás del funcionamiento de operaciones no humanas, algunas de sus omisiones o demoras.

Sin embargo, los propios actores que patrocinaron la causa judicial de Alan y la coalición que le dio impulso tuvieron como objetivo que esta funcionara como "punta de lanza", es decir, que este caso individual se transformara en un litigio estratégico para lograr, no solo que Alan Rodríguez obtuviera su título secundario oficial, sino también la implementación de un cambio normativo más amplio en materia de titulación. En esa línea, la presentación de la demanda incluyó una importante estrategia comunicacional. Alan fue protagonista de entrevistas, reportajes y spots de campañas ${ }^{31}$, con lo que se logró captar la atención de los medios masivos de comunicación ${ }^{32}$. Entre las diversas acciones que se iniciaron, se presentó una petición en la plataforma Change.org donde se reclamaba a las autoridades ministeriales que le otorgaran el título. El pedido fue apoyado por 161173 firmas $^{33}$.

30 Acerca de la "certificacion igualitaria" véase, COPIDIS \& Grupo Artículo 24 (2017, pp.79-82)

31 http://acij.org.ar/demandan-a-la-caba-y-a-una-escuela-por-negar-la-entrega-del-titulo-secundario-a-un-joven-con-discapacidad/

32 Solo a modo de ejemplo, algunas de las apariciones mediáticas del caso: http://www.lanacion.com.ar/1880367-no-tan-incluidos-los-chicos-con-discapacidad-lejos-del-titulo-oficial; http:// telefenoticias.com.ar/actualidad/le-niegan-el-titulo-oficial-a-un-joven-con-sindrome-de-down-quetermino-el-secundario/; http://www.infobae.com/sociedad/2016/10/24/la-justicia-ordeno-que-leden-el-titulo-secundario-a-un-chico-con-sindrome-de-down/

33 https://www.change.org/p/soledad-acunia-por-mi-discapacidad-me-niegan-mi-t\%C3\%ADtulo 
Esta estrategia, que durante el trabajo de campo fue definida por quienes impulsaron la demanda en clave de necesidad de "generar empatía", se potencia y es posible por las habilidades, méritos y logros de Alan que, como se destaca a lo largo de la causa, siempre contó con un entorno familiar que acompañó activamente cada uno de sus espacios formativos en ámbitos inclusivos. Además de ser un buen alumno y obtener destacadas calificaciones, se puso énfasis en su vida social y deportiva, por ejemplo es instructor de tiro con arco -campeón nacional en su categoría de edad, torneo en el que compitió con personas sin discapacidad-, y finalizó las capacitaciones sobre RCP, (recuperación cardiopulmonar).

Esto último resulta destacable. A diferencia de otros litigios con pretensión estratégica en materia de derechos sociales que suelen seleccionar los casos donde los sujetos presentan una acumulación de diversas vulnerabilidades para convertirlos en "merecedores", no solo de bienes o servicios, sino también de la atención de los tribunales de justicia (por ejemplo, "Reyes Aguilera"34, "Quisberth Castro"35), en el caso de Alan, su esfuerzo y sus méritos alimentan las lógicas credencialistas y meritocráticas propias de los sistemas educativos. Recordemos que Alan reclama su título oficial de una escuela común. En este sentido, la propia construcción del caso plantea la siguiente encrucijada: ¿cómo negarle el título a una persona como Alan? ¿Cómo no permitir que un joven con su potencial pueda continuar sus estudios, obtener un empleo?

Durante todo el proceso judicial los representantes del GCBA presentaron sostenidas resistencias que manifestaron no solo en los escritos

34 En el caso "Reyes Aguilera" (Corte Suprema, "Recurso de hecho deducido por Luisa Aguilera Mariaca y Antonio Reyes Barja en representación de Daniela Reyes Aguilera en la causa Reyes Aguilera, Daniela c/ Estado Nacional", 4/09/2007), se discutía la validez de la norma que exigía a una niña en situación de pobreza y con discapacidad física absoluta, el requisito de veinte años de residencia en el país para acceder a una pensión por invalidez. La niña, de nacionalidad boliviana, ya había obtenido su radicación definitiva en Argentina durante 2001. La Corte consideró por mayoría, aunque con fundamentos diversos, que algunas prestaciones sociales no contributivas también están regidas por las obligaciones constitucionales del Estado en materia de seguridad social, en especial cuando esas prestaciones tienden a la protección del derecho a una vida digna de personas con discapacidades físicas.

35 En el caso en el que intervino la Corte (Corte Suprema, "Quisberth Castro, SY c/GCBA s/Amparo", 24/04/2012), esta fijó estándares mínimos sobre el derecho a la vivienda adecuada y ordenó la provisión de un alojamiento adecuado para la actora y su inclusión en un programa de vivienda que le otorgase una solución permanente a su situación habitacional. En este caso, la demandante se encontraba en una situación de extrema vulnerabilidad ("madre en situación de calle con un hijo con discapacidad"). 
judiciales, sino en las audiencias convocadas por la jueza. Una lectura desde los actores de la coalición promotora de la causa sugiere que, a diferencia de otros litigios y aun contando con respaldo mediático y sentencia judicial firme favorable a favor del reclamo de Alan y su familia, las autoridades del GCBA no buscaron revertir su posición. Tampoco capitalizar políticamente el caso "Alan" para dar cuenta de una transformación pionera en educación inclusiva.

A nivel de política pública, este caso impulsó un proceso que ya había comenzado. Se dictaron nuevas resoluciones del Consejo Federal de Educación (resoluciones 311/2016 y 312/2016) que, entre otras cosas, modificaron el sistema federal de títulos ${ }^{36}$. Sintéticamente, el título secundario estará acompañado del certificado analítico donde se dejará constancia del cumplimiento del PPI en el caso de los alumnos con discapacidad, lo que posibilita que el resto de los alumnos del país en situaciones análogas a las de Alan puedan obtener su diploma.

Sin embargo, las piezas burocráticas que organizan la aplicación de la mencionada normativa ("Guía de orientación para la aplicación de la Resolución CFE No. 311/16") permiten dar cuenta de diferentes capas de producción normativa donde se combinan discursos y prácticas que se van alejando del espíritu de educación inclusiva y del enfoque social de discapacidad que motivó las mencionadas resoluciones ${ }^{37}$. A pesar, entonces, de los cambios a nivel de normas de mayor jerarquía, los instrumentos

36 Solo a modo de ejemplo, estas resoluciones forman parte de otro conjunto de normas en materia de educación inclusiva. Por ejemplo, la Resolución 155/2011 dispone que se consideren esencialmente la evaluación pedagógica, el análisis de las barreras al aprendizaje y la participación para la admisión, continuidad y egreso de los/as alumnos/as con discapacidad en las escuelas de educación común y especial. La Resolución No. 174/2012 establece "Pautas federales para el mejoramiento de la enseñanza y el aprendizaje y las trayectorias escolares en el nivel inicial, primario y modalidades, y su regulación". Entre otras cosas, en línea con los principios de la educación inclusiva, recomienda que la trayectoria de alumnos y alumnas con discapacidad será abierta y flexible entre la escuela de educación especial y la de los niveles comunes, privilegiando siempre que sea posible la asistencia a la escuela de educación común.

37 En el Anexo 1 de la mencionada guía (Resolución 2509/17) se incorpora “(...) capacidades que hacen referencia, en sentido amplio, a un conjunto de modos de pensar, actuar y relacionarse que los estudiantes deben tener oportunidad de desarrollar progresivamente a lo largo de su escolaridad, puesto que se consideran relevantes para manejar las situaciones complejas de la vida cotidiana, en cada contexto y momento particular de la vida de las personas: resolución de problemas, pensamiento crítico, aprender a aprender, trabajo con otros, comunicación, compromiso y responsabilidad". A la hora de terminar este trabajo, el Grupo Articulo 24, que tuvo un papel central en el caso aquí analizado, presentó un reclamo administrativo cuestionando dicho instrumento. 
diseñados para darle operatividad consisten en textos que, según nuestros entrevistados, reflejan "cortes y pegues" de antiguas normativas y, por lo tanto, prácticas regresivas. Esto da cuenta de las tensiones que conviven entre diversos enfoques en materia de discapacidad, y que atraviesan los saberes y las prácticas de las burocracias técnico-profesionales que definen y moldean los dispositivos operativos de la política pública como la mencionada guía.

A nivel de la CABA, donde se tramita el caso de Alan, aún queda pendiente el dictado de su propia normativa que reemplace la Disposición 25 y adecúe los contenidos al nuevo escenario de las resoluciones del Consejo Federal de Educación. Mientras tanto, en el marco del expediente judicial, el GCBA presentó un título secundario oficial otorgado a Alan Rodríguez. Este documento, sin embargo, fue rechazado por este y por su familia en tanto fue incorporada una "leyenda" que hace referencia a la Resolución 311 del Consejo Federal de Educación. Este mismo agregado fue también objetado por la Dirección de Validez Nacional de Títulos y Estudios del Ministerio de Educación de la Nación, que sostuvo que dicha inclusión había sido "errónea" porque Alan Rodríguez se graduó con anterioridad a su vigencia, sin dar mayor especificación acerca de los fundamentos ${ }^{38}$. Las medidas judiciales adoptadas posteriormente con el objeto de obtener un pronunciamiento inequívoco de las autoridades nacionales acerca del modo en que debería ser confeccionado el título secundario de Alan Rodríguez, implicaron que, finalmente, el 29 de diciembre de 2017 Alan pudiera tener su título secundario expedido en condiciones de igualdad.

\section{Reflexiones finales}

La reacción de la ministra de Educación del GCBA, ante una pregunta sobre el reclamo de Alan Rodríguez, señalando que "Los títulos no se rifan", da cuenta de la postura de los diferentes actores gubernamentales a lo largo del proceso judicial iniciado a partir de la denegatoria del título secundario luego de haber transitado toda su escolaridad en

38 Esta información consta en el acta de la audiencia celebrada el 2 de agosto de 2017. 
un establecimiento común. La apelación a la rifa (sorteo), al elemento azaroso, refleja una preocupación política y moral por evitar el comportamiento de los "pícaros" (Le Grand, 1998) ${ }^{39}$ que, sin cumplir con las trayectorias educativas "ordinarias", pretenden sortear los criterios meritocráticos y obtener las credenciales en igualdad de condiciones al resto de los alumnos en escuelas comunes. En oposición a esta idea, que busca instalarse desde la dirigencia gubernamental, Alan y su familia se erigen como contrafiguras. Su situación resiste este tipo de argumentos. En la causa se evidencia de qué manera Alan se niega a ser un objeto pasivo, y en el certificado (título secundario) busca no solo el reconocimiento de su recorrido (mecanismo igualador), sino que este le resulta una pieza habilitante para continuar sus estudios y obtener un empleo.

A nivel de política pública, el caso judicial nos habla, como mínimo, de un primer desacople entre el sistema educativo y el nuevo paradigma de la discapacidad que aquí se traduce en clave de otro desacople entre trayectoria escolar y titulación. Este, sin dudas, es un recorte de otras barreras existentes para las personas con discapacidad (adecuaciones normativas, institucionales, edilicias, profesionales, certificaciones). Aunque se trata de un litigio individual, el caso irradia a otras situaciones, traccionando un proceso de transformación normativa en el campo de la educación inclusiva. Una primera mirada sobre el caso muestra su potencialidad para evitar que - a diferencia de otros casos individualesla judicialización se traduzca en mayores desigualdades entre quienes acceden y quienes no a las redes de patrocinio jurídico.

A la vez, una mirada atenta sobre las prácticas burocráticas permite comprender que, si bien los llamados "vacíos normativos" fueron saldados con el surgimiento de las resoluciones (311 y 312 del CFE), en realidad constituyen una estación más en un largo recorrido. Estas transformaciones abrieron un nuevo repertorio de prácticas que se plasman en nuevos instrumentos - por ejemplo, la mencionada "Guía de implementación de las resoluciones"- o discrepancias. De hecho, en el caso de Alan, estas últimas moldean el procedimiento de ejecución de la sentencia en tanto

39 De acuerdo con un texto clásico de David Hume, se encuentran dos categorías de motivaciones y comportamientos humanos: quienes se guían por su exclusivo interés personal (los "pícaros") y los "caballeros" que, a diferencia de aquellos, se inspiran en una ética altruista vinculada con el bien común (Le Grand, 1998). 
se discute, con todos los pormenores, el modo en que su título debe ser confeccionado.

En definitiva, el tipo de abordaje que aquí proponemos insinúa que el caso no es solo relevante por el impacto a nivel individual en la vida de Alan, o por ser el caso testigo de otros casos similares, o, finalmente, por incidir en el proceso de "armonización" de marcos normativos en materia de titulación de personas con discapacidad. Sino también porque este caso da cuenta de un entramado de resistencias y "traducciones" normativas por parte de las burocracias que condensan diversos enfoques y saberes expertos (o no) sobre la discapacidad y convierten a la educación inclusiva en un campo de significados de lo más diverso e incierto.

\section{Referencias}

Abramovich, V. \& Pautassi, L. (2009). El enfoque de derechos y la institucionalidad de las políticas sociales. En V. Abramovich y L. Pautassi (Comps.). La revisión judicial de las políticas sociales. Estudio de casos, (pp. 147-169). Buenos Aires: Del Puerto.

Abramovich, V. \& Pautassi, L. (2008). El derecho a la salud en los tribunales: algunos efectos del activismo judicial sobre el sistema de salud en Argentina. Salud Colectiva, 4(3), 261-282.

Acuña, C. E Bulit Goñi, L. (Comps.). (2010). Política sobre discapacidad en Argentina. El desafio de hacer realidad los derechos. Buenos Aires: Siglo XXI Editores.

Adelantado, J.; Noguera, A.; Rambla, X. \& Sáez, L. (1998). Las relaciones entre estructura y políticas sociales: una propuesta teórica. Revista Mexicana de Sociología, (3), 45-75.

Ainscow, M., Farrell, P. \& Tweddle, D. (2000). Developing policies for inclusive education: A study of the role of local education authorities. International Journal of Inclusive Education, 4(3), 211-229.

Arcidiácono, P. \& Barrera, L. (2017). Trapped in Limbo: Effects of medical perspective on education of children with sisabilities, mimeo.

Arcidiácono, P.; Espejo, N. E Rodríguez Garavito, C. (Coords.). (2010). Derechos sociales: justicia, política y economía en América Latina. Bogotá: Siglo del Hombre Editores. 
Artigas, C. (2005). Una mirada a la protección social desde los derechos humanos y otros contextos internacionales. Serie Políticas Sociales, (110). Santiago de Chile: CEPAL.

Asociación por los Derechos Civiles (ADC). (2015). Manual de buenas prácticas en materia de educación inclusiva. Buenos Aires: ADC.

Auyero, J. (2013). Pacientes del Estado. Buenos Aires: EUDEBA.

Bariffi, F. E Palacios, A. (2012). Capacidad jurídica, discapacidad y derechos humanos. Una revisión desde la Convención Internacional sobre los Derechos de las Personas con Discapacidad. Buenos Aires: EDIAR.

Bercovich, L. E Maurino, G. (Comps.). (2012). Los derechos sociales en la Gran Buenos Aires. Algunas aproximaciones desde la teoría, las instituciones y la acción. Buenos Aires: EUDEBA.

Bergallo, P. (2006). Apuntes sobre justicia y experimentalismo en los remedios frente al litigio de Derecho Público. Revista Jurisprudencia Argentina, 1(1), 207-225.

Bourdieu, P. (2000). La fuerza del derecho. Santa Fe de Bogotá: Editorial Uniandes. Comisión para la Plena Participación e Inclusión de las Personas con Discapacidad (COPIDIS) \& Grupo Artículo 24 por la Educación Inclusiva. (2017). Manual de educación inclusiva. Buenos Aires: COPIDIS.

De Leonardis, O. (1996). Lo público y lo privado. Ábaco. Revista de Cultura y Ciencias Sociales, (9), 12-24.

Dworkin, R. (1984). Los derechos en serio. Barcelona: Ariel Derecho.

Echeita, G. (2008). Inclusión y exclusión educativa. "Voz y quebranto". REICERevista Electrónica Iberoamericana sobre Calidad, Eficacia y Cambio en Educación, 6(2), 9-18.

Grimaldi, V.; Cobeñas, P.; Melchior, M. E Battistuzzi, M. (2016). Construyendo una educación inclusiva: algunas ideas y reflexiones para la transformación de las escuelas y de las prácticas docentes. La Plata: Asociación Azul/ASDRA.

Guber, R. (2010). La etnografía. Buenos Aires: Siglo XXI Editores.

Heller, A. (1996). Una revisión de la teoría de las necesidades. Barcelona: Paidós.

INDEC (Instituto Nacional de Estadística y Censos). Censo Nacional de Población 2010. Recuperado de http://www.indec.gov.ar/nivel4_default.asp?id_ tema_1=2Eid_tema_2=41Gid_tema_3=135

Le Grand, J. (1998). ¿Caballeros, pícaros y subordinados? Acerca del comportamiento humano y la política social. Desarrollo Económico, 38(151), 723-741.

Llewellyn, K. E Hoebel, A. (1941). The Cheyenne way. Conflict and case law in primitive jurisprudence. Berkeley: University of California Press. 
Marcus, G. (1998). Ethnography through thick and thin. Princeton: Princeton University Press.

Ministerio Público Fiscal. (2017). Colección de dictámenes sobre derechos humanos. Cuadernillo 3. Derecho de las personas con discapacidad. Dictámenes del Ministerio Público Fiscal ante la Corte Suprema de Justicia de la Nación (2012-2016).

Monopoli, V. E Arriagada, M. (2013). Discapacidad psicosocial, salud mental y no discriminación. La Convención sobre los Derechos de las Personas con Discapacidad y la Ley Nacional de Salud Mental como herramientas para la igualdad. Algunos avances del Estado argentino. En P. Rosales (Dir.). Discapacidad, Justicia y Estado. Discriminación, estereotipos y toma de conciencia, (pp. 123-149). Buenos Aires: Infojus.

Nader, L. (Comp.). (1969). Law in culture and society. Berkeley: University of California Press.

O’Donnell, G. (2008). Epílogo. En R. Sieder, L. Schjolden y A. Angell (Eds.). La judicialización de la política en América Latina, Bogotá: Universidad Externado de Colombia.

Palacios, A. (2008). El modelo social de discapacidad: origenes, caracterización y plasmación en la Convención Internacional sobre los Derechos de las Personas con Discapacidad. Madrid: Ediciones Cinca.

Sarrabayrouse Oliveira, M. J. (2011). Poder judicial y dictadura. El caso de la Morgue. Buenos Aires: CELS/ Editores del Puerto, Colección Revés Antropología y Derechos Humanos.

Skliar, C. (2005). Poner en tela de juicio la normalidad, no la anormalidad. Políticas y falta de políticas en relación con las diferencias en educación. Revista Educación y Pedagogía, XV(41), 11-22.

Smulovitz, C. (2008). La política por otros medios: judicialización y movilización legal en Argentina. Desarrollo Económico, (48), 287-305.

UNESCO. (2005). Guidelines for inclusión: Ensuring access to education for All. París: UNESCO. Recuperado de http://unesco.org/educacion/inclusive

Venturiello, M. P. (2016). La trama social de la discapacidad: cuerpo, redes familiares y vida cotidiana. Buenos Aires: Biblos. 